\title{
Use of Mineral Trioxide Aggregate in the Treatment of Large Periapical Lesions: Reports of Three Cases
}

Tahsin Yildirim ${ }^{a}$

Nimet Gencoglu

\begin{abstract}
Pulpal and periradicular pathosis are the result of microbial, mechanical, or chemical invasion. Microorganisms are the main irritants of pulpal and periapical tissues. The goal of the obturation is to obtain a fluid-tight seal of the root canal system from its coronal aspect through its apical extent to preserve from the irritants.. Root apices have morphological irregularities in teeth with periapical lesions. Therefore, it is more difficult to produce hermetically apical stop with conventional guttapercha obturation techniques. This case report describes the treatment and six years follow-up of the teeth with large periapical lesion using MTA as apical filling material. (Eur J Dent 2010;4:468474)
\end{abstract}

Key words: Mineral trioxide aggregate; Obturation; Periapical lesion; Root canal treatment.

\section{INTRODUCTION}

The goal of the obturation is to obtain a fluidtight seal of the root canal system from its coronal aspect through its apical extent. ${ }^{1}$ Inadequate obturation can result in the movement of oral fluids into voids in the obturated root canal and the induction of a periapical inflammatory reaction. ${ }^{1,2}$ The integrity of the root canal filling in the apical

\footnotetext{
Associate Professor, Karadeniz Technical University, Faculty of Dentistry, Department of Restorative Dentistry, Trabzon, Turkey.

b Professor, Marmara University, Faculty of Dentistry, Department of Endodontics, Istanbul, Turkey.

- Corresponding author: Tahsin Yildirim Karadeniz Technical University, Faculty of Dentistry, Department of Restorative Dentistry, Trabzon, Turkey. Phone: +90 4623774733 Fax: +90 4623253017

E-mail: tahsinylahotmail.com tahsinyaktu.edu.tr
}

few millimeters is believed to be one of the criteria necessary to ensure successful endodontic treatment. ${ }^{3}$ The properties of ideal root filling materials include the ability to adhere and seal the root canal system hermetically, non-toxicity and toleration of periradicular tissues, dimensional stability, nonresorbability, and resistance to the presence of moisture. ${ }^{4}$

Lateral compaction is the most frequently used obturation technique involving the use of gutta-percha cones compacted into the root canal with sealing cement in the treatment of teeth with large periapical lesions. But this technique contains more sealer proportion, ${ }^{5}$ also the sealer can be resorb with time, ${ }^{6}$ and this may result in the failure of the root canal treatment.

MTA has proven to have several potential clini- 
cal applications due to its superior sealing property, ability to set in the presence of blood, ${ }^{7}$ bactericidal effects, and biocompatibility ${ }^{8}$ and new cement formation. ${ }^{9}$ Torabinejad and Chivian ${ }^{10}$ have suggested the use of MTA as an obturating material for the entire root canal system. Holland et al $^{11,12}$ used MTA material in root canal treatment as filling material with gutta-percha in dogs' teeth. They showed that MTA was histologically successful when it was used for root filling material and showed apical foramen was closed completely with new cement formation. O'Sullivan and Hartwell ${ }^{13}$ used MTA as filling material in the treatment of retained primary molar tooth and informed that technique seemed to provide a biocompatible seal of the root canal system in that case. However, MTA has not been used clinically in the treatment of teeth with periapical lesions until now.

This case report presents three successful treatment and six years follow-up of the teeth with large periapical lesions using MTA as orthograde apical sealing material.

\section{CASE REPORTS}

Case 1

In 2002, a 37-year-old female patient presented to the Endodontic Department of Marmara University's Faculty of Dentistry with aesthetic concerns due to the loss of coronal segment of the left mandibular lateral and canine teeth (\#22 and \#23). Radiographic examination of the teeth showed large periapical lesion in teeth numbered 22 and 23 (Figure 1a).

\section{Case 2}

In 2002, a 17-year-old male patient presented to the Endodontic Department of Marmara University's Faculty of Dentistry with aesthetic concerns resulting from the orthodontic disorders of the teeth. In the radiographic examination, large periapical lesion was diagnosed in the tooth \#7 of the patient (Figure 2a). The patient's history included a traumatic injury when he was 12 years old. But there was no discoloration in the tooth.

\section{Case 3}

In 2002, a 48-year-old male patient presented to the Endodontic Department of Marmara University's Faculty of Dentistry after an uncompleted treatment he had undergone. In his anamnesis it was found out that he had started to have a root canal treatment in tooth \#29 but he had left the treatment unfinished. In the clinical examination, temporary restoration was observed on the tooth. It was not any clinical symptom in the tooth. In the radiographical examination, periapical lesion was diagnosed in tooth \#29 (Figure 3a).

All the teeth with large periapical lesion gave negative response to the palpation and percussion tests. Root canal treatments of the teeth in each patient were planned. The treatment plan was explained to the patients and permissions were granted.

Rubber dam was applied for all teeth. A conventional endodontic access was prepared in each tooth and a size $20 \mathrm{~K}$-file (Kerr, Romulus, MI) was inserted to determine the location of the apical foramen and radiograph was taken. The teeth were instrumented to ISO size 50 using the step-back technique combined with $2.5 \%$ sodium hypochlorite irrigation. After the preparation, the canal was filled with $\mathrm{Ca}(\mathrm{OH})_{2}$ and access cavity was filled with temporary filling material (Cavit G; 3M Espe, Seefeld, Germanyl. Next visit, $\mathrm{Ca}(\mathrm{OH})_{2}$ was removed from the canal and finally the tooth was irrigated with $2.5 \% \mathrm{NaOCl}$ and dried with paper point and grey MTA (Dentsply Tulsa Dental Specialties, Tulsa, OKJ was applied as follows for each tooth:

A root canal Messing gun (Dentsply Maillefer, Ballaigues, Switzerland) was prepared. An endodontic plugger appropriate to working length was chosen and a stopper was placed $1 \mathrm{~mm}$ behind the working length. MTA was prepared according to the manufacturer's recommendations by mixing with the proportion of $1 / 3$. MTA was applied to the root canal of the tooth using the messing gun, and it was pushed into the apical $1 \mathrm{~mm}$ part of the tooth by the plugger. A large gutta-percha point was also used to insert the MTA within the apical area. Radiography was taken to assure control of the obturation. Then, the plugger was fixed $2 \mathrm{~mm}$ behind the working length, and the same application was repeated.

In case 1, interval of visit was 1 month because the patient didn't come to appointment earlier. The teeth were obturated about 1-2 mm apical filling in case 1 . In case 3 , apical filling was performed about $3 \mathrm{~mm}$. In case 2 apical filling with MTA was performed about 4-5 mm. After the MTA application, a moistened cotton pellet was placed 


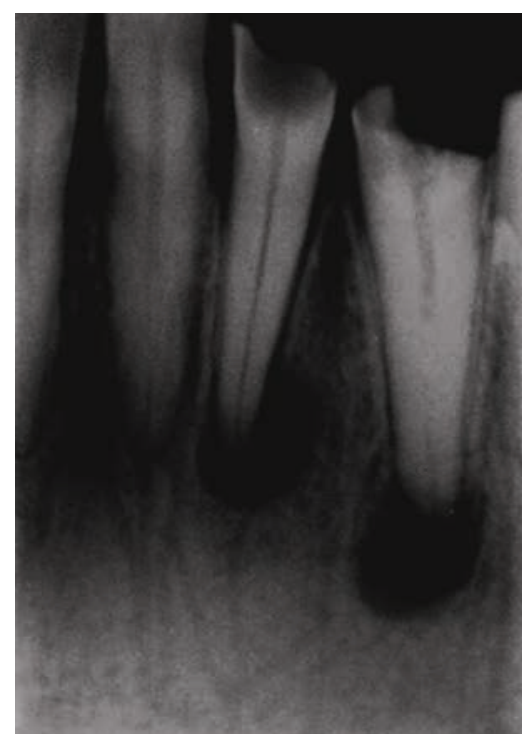

Figure 1a. Lower left lateral and canine teeth with large periapical lesion (\#22, 23). Age 37, female patient.

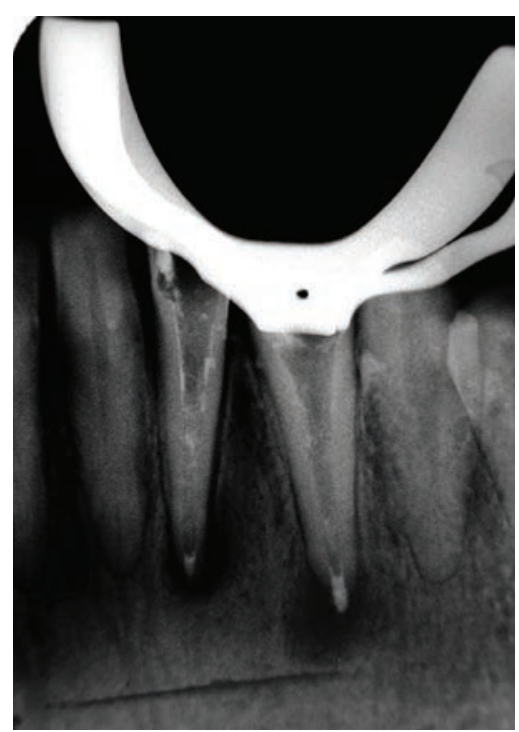

Figure 1b. MTA application to the teeth

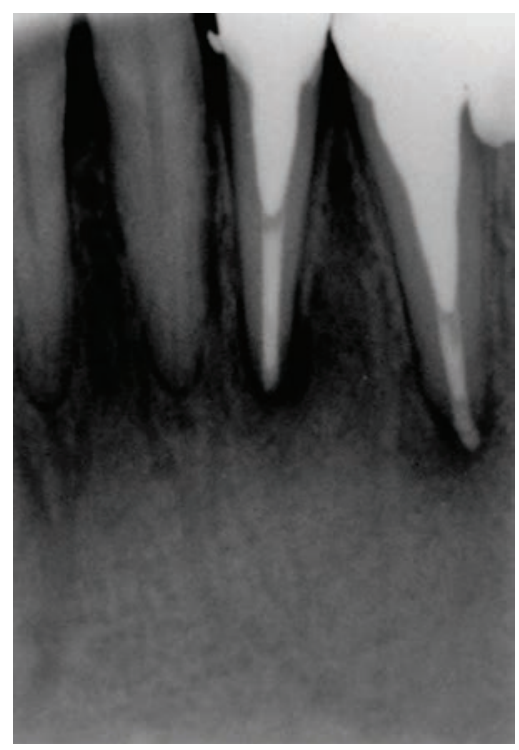

Figure 1e. 1 year. Periapical lesion was decreased but not dissolved completely. on MTA and the endodontic access cavity was filled with Cavit G. On the next visit, the cotton pellet was removed and $\mathrm{H}$-files were used to eliminate the remaining MTA remnant in the canal walls with circumferential movement. Finally the tooth was irrigated with $2.5 \% \mathrm{NaOCl}$ and dried with paper point and the remaining portion of the tooth was filled with gutta-percha and sealer.

Radiograph was taken again to control the obturation (Figure 1bc, 2bc, 3b).

In case 2 and 3 ; final coronal restoration were applied with composite resin. In case 1 ; the patient was send to the prosthetic department to perform crown restoration. The teeth were followed-up clinically and radiographically from 6 months to 6 years (Figures 1d, 1e, 1f, 1g, 2d, 2e, 2f, 3c, 3d, 3e and $3 \mathrm{fl}$.

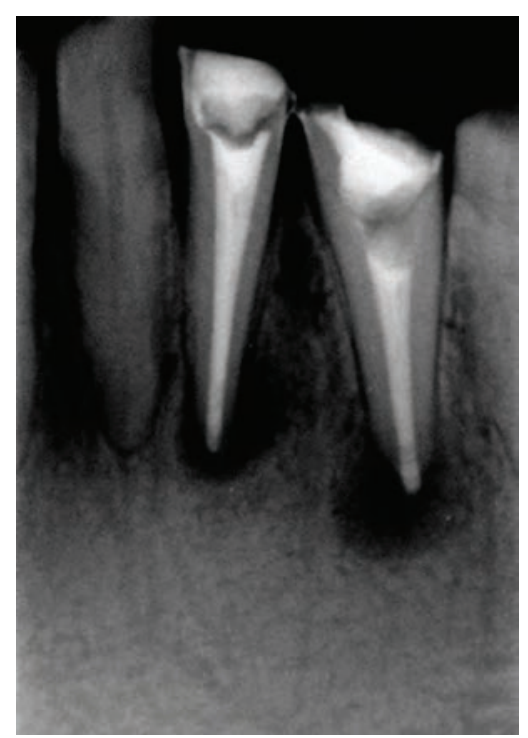

Figure 1c. Root canal filling was performed. Excess material was seen in tooth \#23.

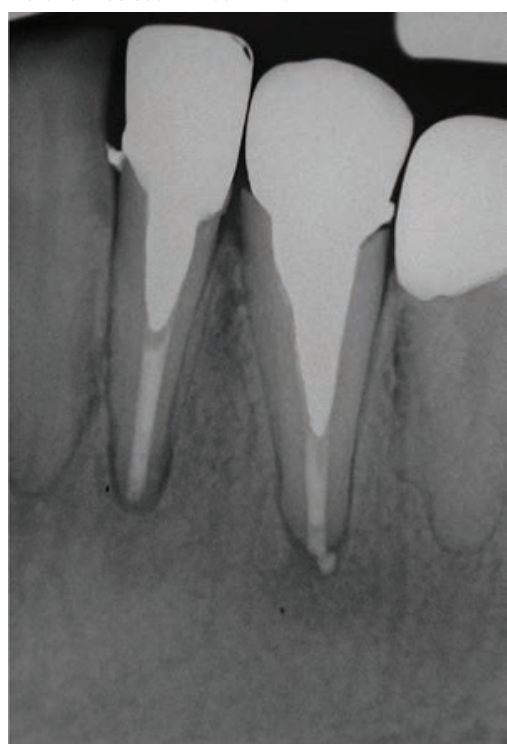

Figure 1f. 2 years later. It is seen that lesion was completely healed radiographically.

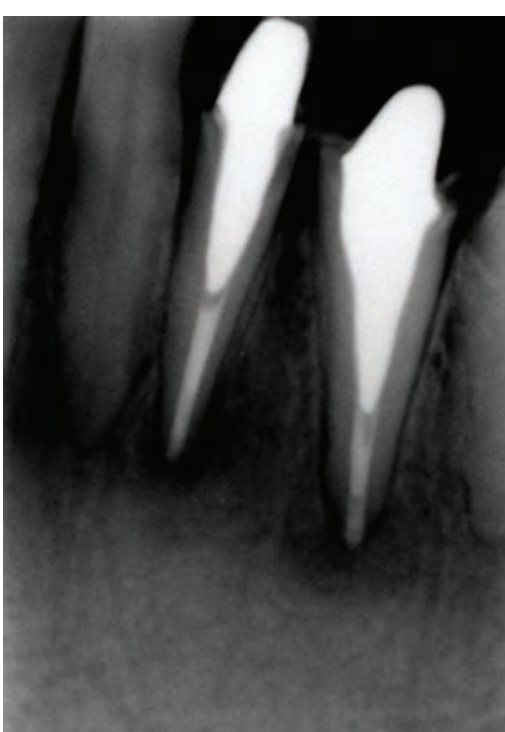

Figure 1d. 7 months later. It is seen that periapical le sion was little dissolved at seven months.

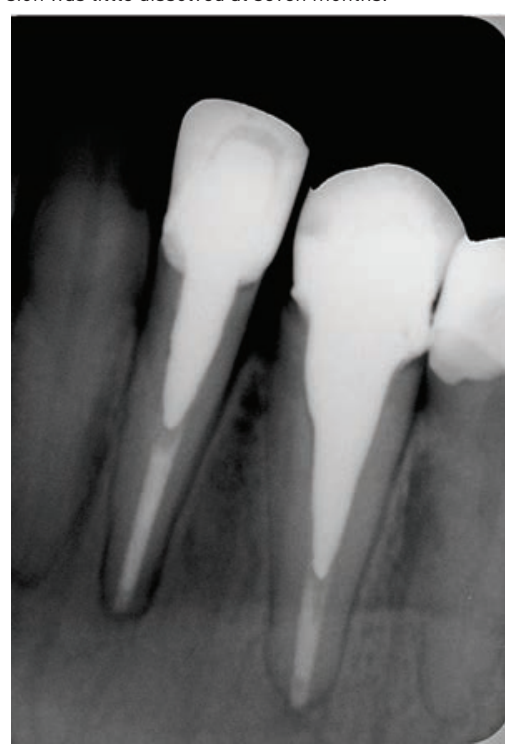

Figure $1 \mathrm{~g} .6$ years. The tooth was stabil and no periapical lesion was seen. 
All teeth were clinically asymptomatic at the beginning of the 6-month period, and periapical lesion was completely dissolved in case 2 in 6 months; in case 1 and case 3 in 2 years.

In addition in follow up of the patient of case 2 , it was seen orthodontic treatment has just finished. Also, surprisingly in 6 years follow-up of case 3 ; it was seen that the patient got full crown restoration done to his teeth. Mandibular bone necrosis was seen caused by use of arsenic paste during endodontic treatment due to inadequate access cavity preparation over the crown in the right first mandibular molar tooth (Figure 4).

\section{DISCUSSION}

Apical periodontitis is a pulpally related inflammation of the attachment apparatus of the tooth. Untreated pulpal inflammation is gradually spread beyond the apex of the tooth. The resorption of cementum (and dentin) and alveolar bone is seen. ${ }^{14}$ Along with the process of resorption, some apical parts of the root will be lost as well. The original configuration of the apical canal anatomy is altered. ${ }^{15}$ Therefore, it is difficult to produce hermetically apical stop and root canal treatment may be more difficult with conventional gutta-percha obturation techniques in the teeth with periapical lesion.

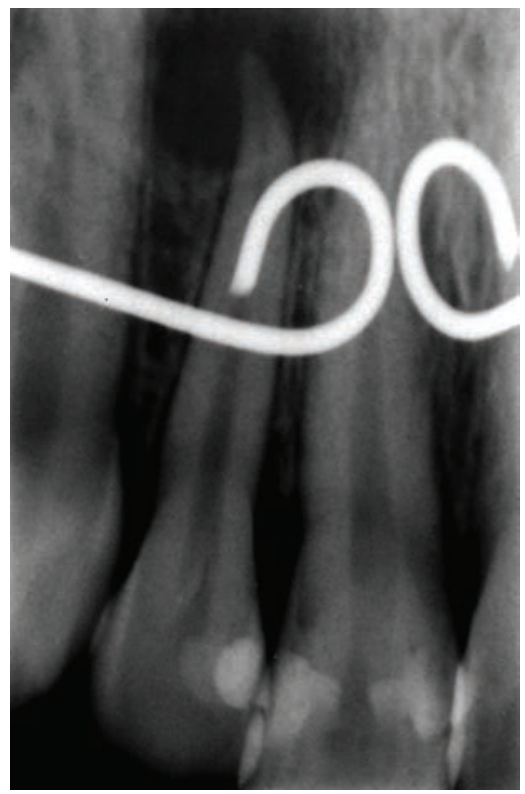

Figure 2a. Upper right central tooth with large periapical lesion (\#7). Age 17, female patient.

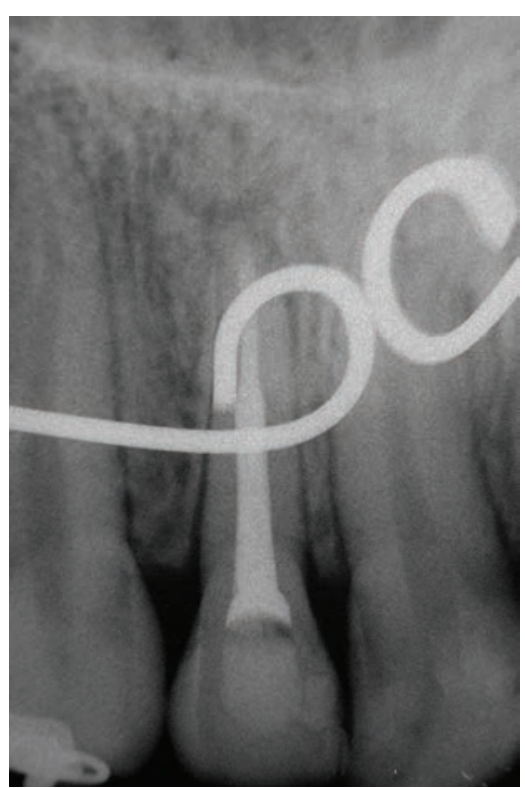

Figure 2d. 6 months later. Periapical lesion was dissolved.

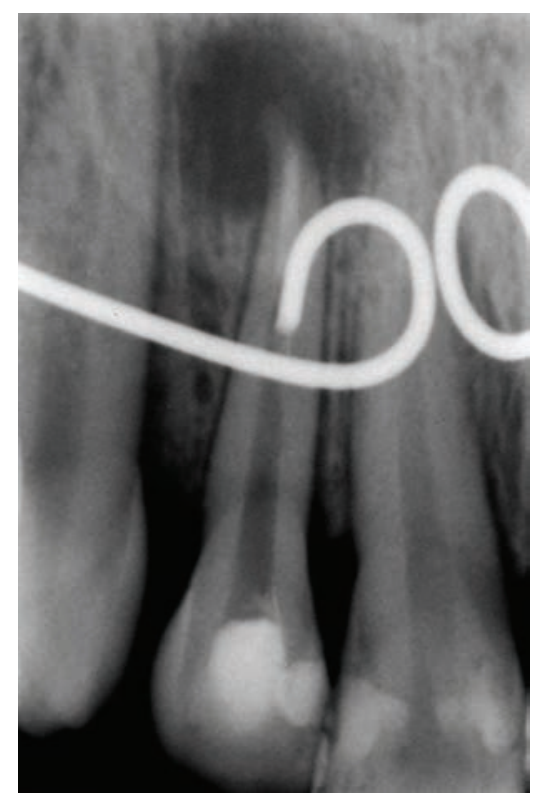

Figure 2b. MTA was applied to the root canal as apical plug approximately $5 \mathrm{~mm}$

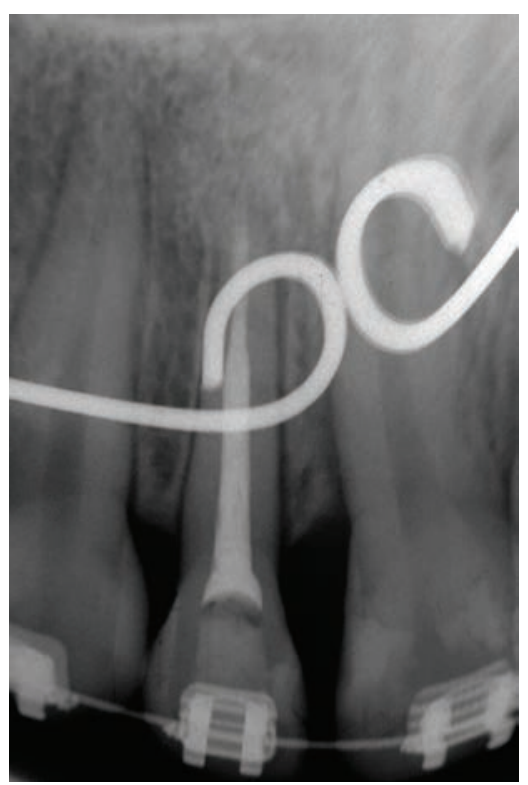

Figure 2e. 12 months later.

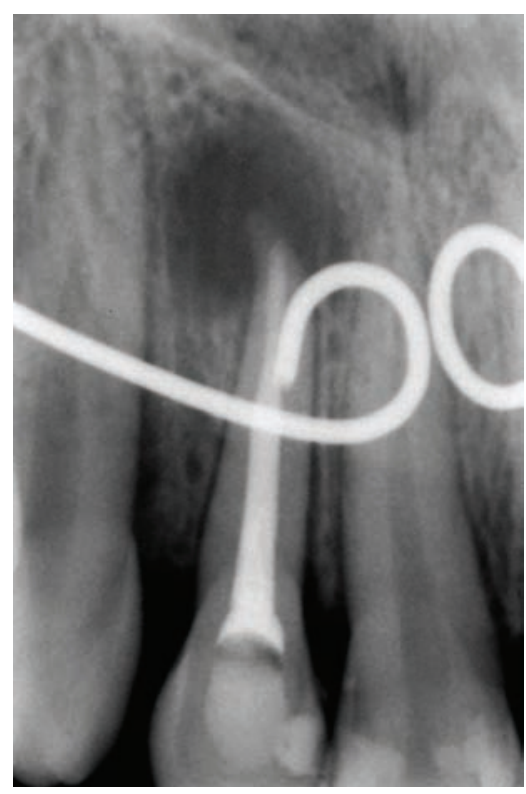

Figure 2c. Coronal portion of the tooth was filled with guta-percha and sealer.

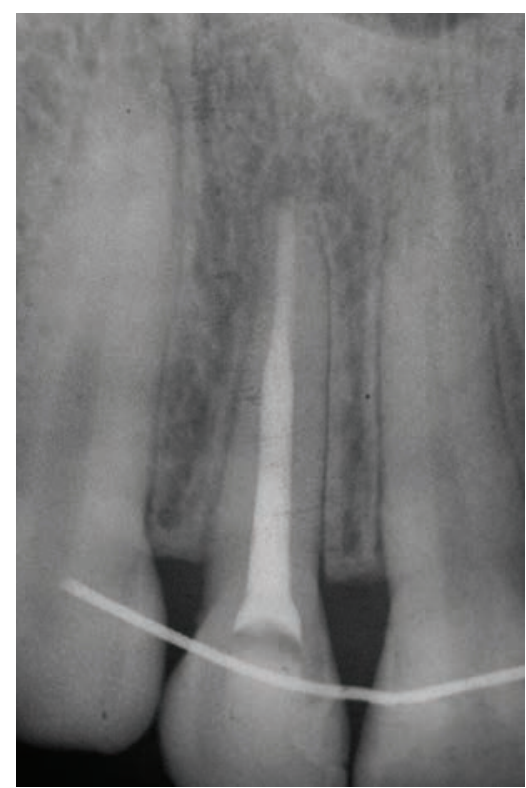

Figure 2f. 6 years later. The appearance of the tooth. 
Lateral compaction has been frequently used in the obturation of teeth with periapical lesions. But Eguchi et $\mathrm{al}^{5}$ stated that as there is more sealer proportion in the lateral compaction, there might be some voids in the root canal. Peters ${ }^{6}$ also stated that the sealer could be resorbed with time. Sealer dissolution may trigger an increase in leakage along the root fillings over time ${ }^{16}$ and this could adversely affect the long-term success of the root canal filling.

MTA has good sealing ability even in moistened area, ${ }^{7}$ good marginal adaptation, ${ }^{17}$ and high biocompatibility. 9,11,12,18 The application of apical plug with MTA may create adequate apical seal, and may limit bacterial infection ${ }^{7}$ in these teeth. MTA has been used and informed successful results when applied as apical plug in the treatments of the teeth with non-vital and open apices. ${ }^{10,19,20}$ However, there is no research or report about the use of MTA in the treatment of the teeth with large periapical lesion. Therefore, we used the MTA for this reason and these cases showed that MTA is a successful material in the long-term in the treatment of the teeth with large periapical lesions when applied in the root canal.

As one of the aim of root canal treatment is to prevent the re-infection of the root canal system, MTA is one of the best material can be used for this purpose. MTA has shown to stimulate the formation of new hard tissue at the surface where the MTA material touches. ${ }^{9,11,12,18}$ Holland et al ${ }^{11,12}$ used MTA material in root canal treatment as sealer in dogs' teeth. They showed apical foramen was closed completely with new cement formation using MTA. So it is expected that the root end of the teeth filled with MTA may be surrounded with new hard tissue in human teeth. Yildirim et $\mathrm{al}^{21}$ used MTA in the treatment of the horizontal root fracture as apical plug. After a follow-up that lasted for 5 years, they showed new hard tissue formation around the MTA material radiographically. This data justifies the findings in the animal studies. 9,11,12,18 Therefore, the use of MTA may help to prevent the re-infection in the teeth with large perapical lesions.

The thickness of the apical filling was approximately 1 to $5 \mathrm{~mm}$ in our teeth. Mattison et $\mathrm{al}^{22}$ stated that at least $5 \mathrm{~mm}$ gutta-percha is necessary for an adequate apical seal. Valois and Cos$\mathrm{ta}^{23}$ investigated the influence of the thickness of mineral trioxide aggregate (MTA) on sealing ability of root-end fillings in vitro. They found that a thickness of $4 \mathrm{~mm}$ is most adequate for the use of MTA as a root-end filling material compared to 3,2 and $1 \mathrm{~mm}$. Martin et $\mathrm{al}^{24}$ concluded that a 3to 5-mm-thick MTA orthograde apical plug that is recommended by the manufacturer for one-visit apexification produces a reasonable seal. When we started the treatment of large periapical lesion using MTA, there was no study related to apical plug or filling thickness of MTA. Therefore, we did not consider the thickness of material. We

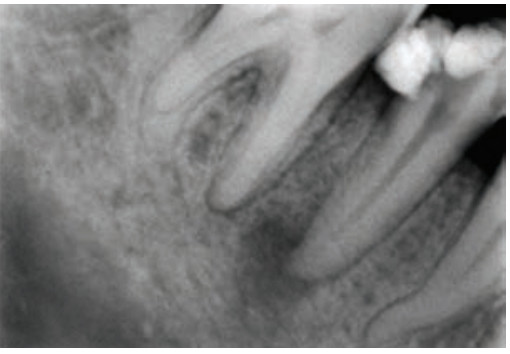

Figure 3a. Lower second premolar tooth (\#29). Age 48, male patient.

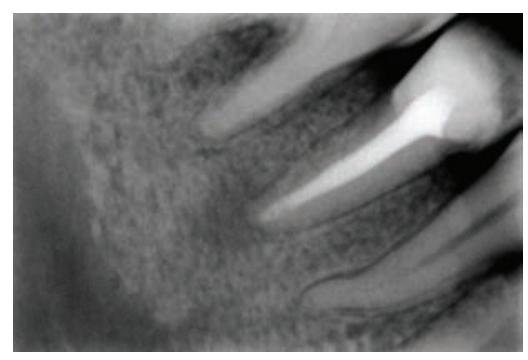

Figure 3d. 12 months later. Lesion was little dissolved

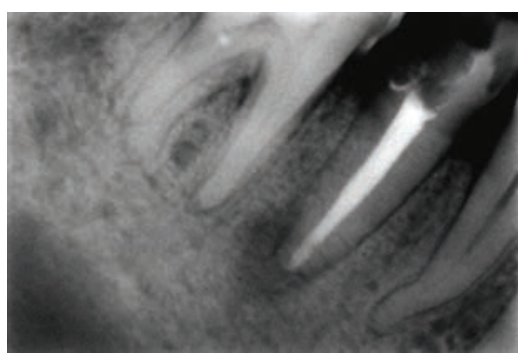

Figure $3 b$. After the root canal filling. MTA was appli approximately $2,3 \mathrm{~mm}$.

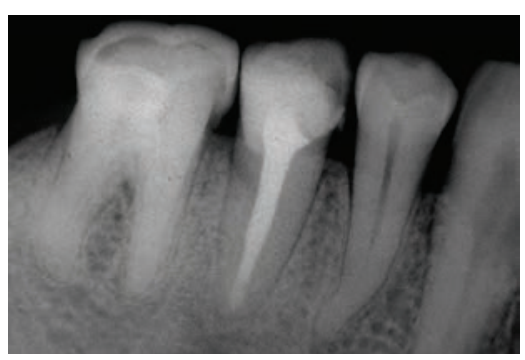

Figure 3e. 24 months. Periapical lesion was completely healed.

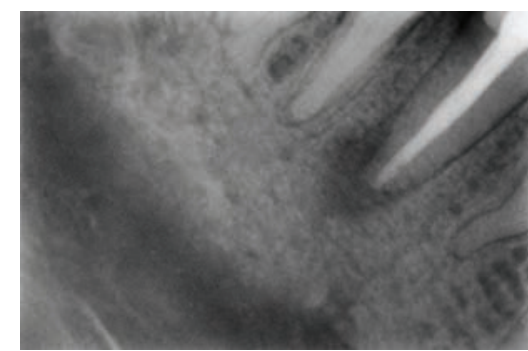

Figure 3c. 6 months later.

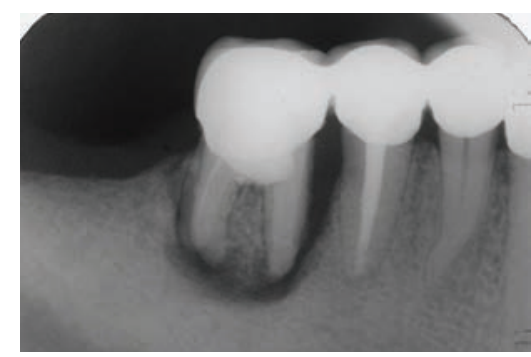

Figure 3f. 6 years later. Lesion was completely healed. But surprisingly heavy bone necrosis is seen in tooth $\# 30$. The tooth \#30 was extracted. 
only aimed to obtain a hermetic plug with MTA. In our cases only one tooth was filled as $5 \mathrm{~mm}$ apical filling and periapical lesion of the tooth was completely healed in 6 months. Also the age of the patient was 17. In the other patients the teeth were filled about 1-3 mm apical filling with MTA and the lesions of the teeth were completely healed in 2 years. And ages of the patients were 37 and 48 . Sjogren et $\mathrm{al}^{25}$ evaluated the influence of various factors that may affect the outcome of root canal therapy in 356 patients 8 to $10 \mathrm{yr}$ after the treatment. They informed there were no statistically effect of age and gender of patients on the success of periapical healing. These results can consider that the thickness of MTA material in root canal may be a factor effecting the healing of the large periapical lesion. But, in our cases, 4 teeth of 3 patients are not enough to asses the effect of thickness on healing. Further research is needed to evaluate the effect of thickness of MTA on healing clinically.

When we started the root canal filling with MTA in the clinic, there was only grey MTA on the market. We applied the grey MTA in the root canal about as 2-5 $\mathrm{mm}$ apical filling and filled remained canal with gutta-percha and sealer. We didn't fill the whole canal with MTA. Martin et $a^{24}$ investigated the effect of apical plug and root filling application on the apical sealing ability of the MTA using fluid filtration method. They informed there is no difference between the applications after 1 month. Besides, Boutsioukis et $\mathrm{al}^{26}$ reported that MTA was difficult to be removed when it was used along the whole root canal. Bortoluzzi et $\mathrm{al}^{27}$ also informed that grey MTA applied in the coronal region of the root canal caused discoloration. Con-

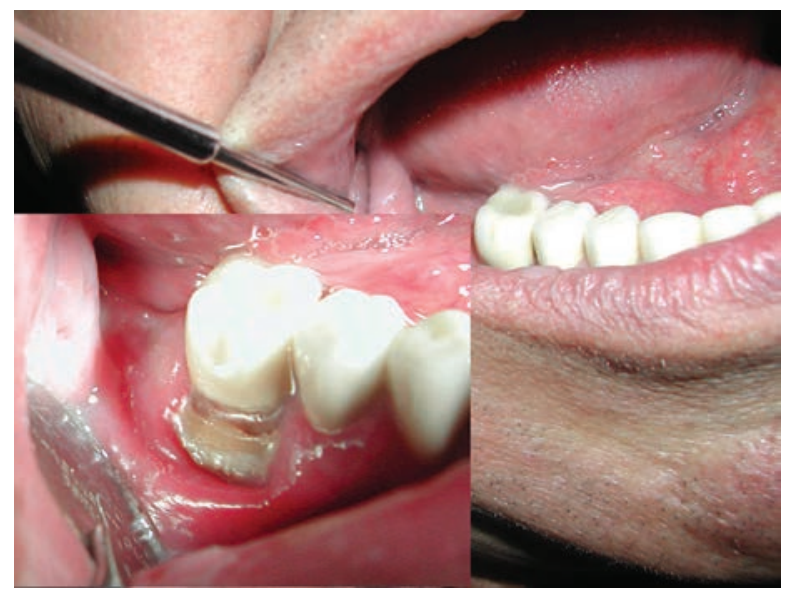

Figure 4. Mandibular bone necrosis was seen caused by use of arsenic paste during endodontic treatment due to inadequate access cavity preparation over the crown. sequently, it seems it may be more appropriate to fill the only apical part of the root canal with MTA. When the MTA is filled as $5 \mathrm{~mm}$ apically, if the treatment goes to failure and root-end resection had to be performed after the treatment, no retrograde filling would have to be placed at the time of surgery. ${ }^{28}$

Healing of periapical lesions is a dynamic event and its duration changes from case to case. Longterm observation, especially a length of six years, is an important time for the assessment of the quality and reliability of materials or techniques. There have been studies that have been followed for up to 27 years. ${ }^{29}$ However, Ingle ${ }^{30}$ based a follow-up period of 2 years for evaluating whether a treatment is successful or not. The follow-up period in the literature for MTA applications were generally applied only one or two years in different studies. ${ }^{31,32}$ We observed the patients for six years. The present case report is the first of its kind in which MTA is used clinically and followed up for six years using an apical filling material for root canal treatment of teeth with large periapical lesions.

\section{CONCLUSIONS}

The use of MTA in the treatment of large periapical lesion is not a routine application; however, MTA positively affected the healing of the teeth with the lesion after 6 years so it may be concluded that it can be used clinically in the treatment of the teeth with large periapical lesion. These results may lead the way for further studies in this field. Further researches are needed to evaluate the use of MTA in the root canal.

\section{REFERENCES}

1. Schilder H. Filling root canals in three dimensions. Dent Clin North Am 1967;11:723-745.

2. Cohen S, Burns R. Pathways of the pulp 6th ed. St. Louis: C.V. Mosby Co. 1994;219-220.

3. The SD. Sectional gutta-percha point, second apical seal, and coating of the inner dentinal walls. Oral Surg Oral Med Oral Pathol Oral Radiol Endod 1979;47:555-557.

4. Dorn SO, Gartner AH. Retrograde filling materials: a retrospective success-failure study of amalgam, EBA, and IRM. J Endod 1990;16:391-393. 
5. Eguchi DS, Peters D, Hollinger JO, Lorton L. A comparison of the area of the canal space occupied by gutta-percha following four gutta-percha obturation techniques using procosol sealer. J Endod 1985;11:66-75.

6. Peters DD. Two year in vitro solubility evaluation of four guttapercha sealer obturation techniques. $J$ Endod 1986;12:139-145.

7. Torabinejad M, Higa RK, McKendry DJ, Pitt Ford TR. Dye leakage of four root end filling materials: effects of blood contamination. J Endod 1994;20:159-163.

8. Torabinejad M, Hong CU, Pitt Ford TR, Kettering JD. Antibacterial effects of some root end filling materials. J Endod 1995;21:403-406.

9. Yildirim T, Gencoglu N, Firat I, Guzel O, Perk C. Histologic study of furcation perforation treated with MTA or Super EBA in dog's teeth. Oral Surg Oral Med Oral Pathol Oral Radiol Endod 2005;100:120-124.

10. Torabinejad M, Chivian N. Clinical applications of mineral trioxide aggregate. Review. J Endod 1999;25:197-205.

11. Holland R, de Souza V, Nery MJ, Otoboni Filho JA, Bernabé PF, Dezan Júnior E. Reaction of dogs' teeth to root canal filling with mineral trioxide aggregate or a glass ionomer sealer. J Endod 1999;25:728-730.

12. Holland R, Mazuqueli L, de Souza V, Murata SS, Júnior ED, Suzuki P. Influence of the type of vehicle and limit of obturation on apical and periapical tissue response in dogs teeth after root canal filling with mineral trioxide aggregate $J$ Endod 2007;33:693-697.

13. O'Sullivan SM, Hartwell GR. Obturation of a retained primary mandibular second molar using mineral trioxide aggregate: a case report. J Endod 2001;27:703-705.

14. Tronstad L (ed). Clinical endodontics. New York: Thieme, New York, 3rd ed., 2008

15. Bergenholtz G, HB Preven, Reit C. Textbook of Endodontology Blackwell Munksgard 2003 Chapter 9 Apical periodontitis. Risto-Pekka Happonen and Gunnar Bergenholtz, p.130-144.

16. Kontakiotis EG, Wu MK, Wesselink PR. Effect of sealer thickness on long-term sealing ability: a 2-year follow-up study. Int End J 1997;30:307-312.

17. Torabinejad M, Smith PW, Kettering JD, Pitt Ford TR. Comparative investigation of marginal adaptation of mineral trioxide aggregate and other commonly used root-end filling materials. J Endod 1995;21:295-299.

18. Pitt Ford TR, Torabinejad M, McKendry DJ, Hong CU, Kariyawasam SP. Use of mineral trioxide aggregate for repair of furcal perforations. Oral Surg Oral Med Oral Pathol Oral Radiol Endod 1995;79:756-763.
19. Giuliani V, Bacetti T, Pace R, Papavino G. The use of MTA in teeth with necrotic pulps and open apices. Dent Traumatol 2002;18:217-221.

20. Hayashi M, Shimizu A, Ebisu S. MTA for obturation of mandibular central incisors with open apices: Case report. $J$ Endod 2004;30:120-122.

21. Yildirim T, Gençoḡlu N. Use of mineral trioxide aggregate in the treatment of horizontal root fractures with a 5-year follow-up: report of a case. J Endod 2009;35:292-295.

22. Mattison GD, Selivanis PD, Thacker RW, Hassel KJ. Effect of post preparation on the apical seal. J Prosthet Dent 1984;51:785-789.

23. Valois CR, Costa ED Jr. Influence of the thickness of mineral trioxide aggregate on sealing ability of root-end fillings in vitro. Oral Surg Oral Med Oral Pathol Oral Radiol Endod 2004;97:108-111.

24. Martin RL, Monticelli F, Brackett WW, Loushine RJ, Rockman RA, Ferrari M, Pashley DH, Tay FR. Sealing properties of mineral trioxide aggregate orthograde apical plugs and root fillings in an in vitro apexification model. $J$ Endod 2007;33:272-275.

25. Sjogren U, Hagglund B, Sundqvist G, Wing K. Factors affecting the long-term results of endodontic treatment. $J$ Endod 1990;16:498-504.

26. Boutsioukis C, Noula G, Lambrianidis T. Ex vivo study of the efficiency of two techniques for the removal of mineral trioxide aggregate used as a root canal filling material. $J$ Endod 2008;34:1239-1242.

27. Bortoluzzi EA, Araújo GS, Guerreiro Tanomaru JM, Tanomaru-Filho M. Marginal gingiva discoloration by gray MTA: a case report. $J$ Endod 2007;33:325-327.

28. Matt GD, Thorpe JR, Strother JM, McClanahan SB. Comparative study of white and gray mineral trioxide aggregate (MTA) simulating a one- or two-step apical barrier technique. J Endod 2004;30:876-879.

29. Molven O, Halse A, Fristad I, MacDonald-Jankowski D. Periapical changes following root-canal treatment observed 20-27 years postoperatively. Int End J 2002;35,784790.

30. Ingle JI. Modern endodontic therapy. In: Ingle JI, Taintor JF eds. Endodontics 3rd ed. Philadelphia, Lea \& Febiger, p. 439-70,1988.

31. Sonmez D, Sari S, Cetinbas T. A Comparison of four pulpotomy techniques in primary molars: a long-term followup. J Endod 2008;34:950-955.

32. Kusgoz A, Yildirim T, Tanriver M, Yesilyurt C. Treatment of horizontal root fractures using MTA as apical plug: report of 3 cases. Oral Surg Oral Med Oral Pathol Oral Radiol Endod 2009; 107:e68-e72. 